\title{
A Crise de 2008 e a Arquitetura Financeira Internacional: Propostas de Regulação do G-20 e seus Desafios
}

\section{The 2008 Crisis and the International Financial Architecture: Regulation Proposals of the G-20 and its Challenges}

Rúbia Marcussi Pontes ${ }^{\mathrm{a}}$ iti Olívia Bullio Mattos ${ }^{\mathrm{b}}$

\begin{abstract}
Resumo: Os efeitos da crise financeira e econômica de 2007 e 2008 na arquitetura financeira internacional demonstraram que os acordos de regulação postos até aquele momento não eram infalíveis. A partir disso, o presente artigo tem como objetivo principal demonstrar como o Grupo dos 20 (G-20) atuou após a eclosão da crise na busca de uma articulação política para formular uma nova proposta de regulação, que promoveria maior resiliência ao sistema. Entretanto, os interesses estratégicos nacionais e a própria prerrogativa de implementação dos acordos, que é feita de forma nacional, são desafios enfrentados na busca por maior estabilidade financeira. Ressaltase, assim, que mudanças no arcabouço regulatório internacional ocorreram a partir da articulação do G-20 com outras instâncias, dando origem ao Acordo de Basileia III, porém a natureza instável do sistema persiste.
\end{abstract}

Palavras-chave: Grupo dos 20 (G-20). Crise financeira (2007/2008). Regulação internacional. Acordos de Basileia.

\begin{abstract}
The effects of the financial and economic crisis of 2007 and 2008 in the international finance architecture demonstrated that the regulation accords implemented up to that moment were not risk-free. Being said that, this article aims to demonstrate how the Group of 20 (G-20) acted after the crisis seeking a political articulation and a new proposal of international regulation, which would increase the resilience of the system. However, the national strategic interests and the fact that countries need to implement the accords internally are challenges faced in the search for broader financial stability. Changes in the international regulations were fulfilled with the work of the G-20 with other instances, which originated Basel III; nevertheless, the instable nature of the system remains the same.
\end{abstract}

Keywords: Group of 20 (G-20). Financial crisis (2007/2008). International regulation. Basel Accords.

JEL Classification: F5; F55.

a Universidade Estadual de Campinas (UNICAMP), Instituto de Filosofia e Ciência Política (IFCH), Departamento de Ciência Política. São Paulo, Brasil.

b St. Francis College, Departamento de Economia, História e Ciência Política. Brooklyn, Nova Iorque, Estados Unidos. 


\section{1 lntrodução}

Os efeitos da crise financeira e econômica iniciada nos Estados Unidos em meados de 2007 e 2008 não foram pontuais, mas sim de cunho sistêmico, afetando não somente a economia norte-americana, mas também o sistema financeiro e monetário internacional (SFMI), o que demandou que iniciativas em âmbito multilateral e planos de ação que buscassem a coordenação de políticas econômicas fossem debatidos em diversos fóruns, com distintas abordagens.

Nesse sentido, uma das instâncias mais utilizadas para discussão foi o Grupo dos 20 (G-20), que se sobressaiu como um fórum "[...] de cooperação e consulta sobre assuntos do sistema financeiro internacional e da gestão macroeconômica da crise [...]" (FARHI, 2011, p. 8), com membros que representavam aproximadamente $90 \%$ do PIB mundial e $80 \%$ do comércio internacional. O G-20 já possuía um histórico de atuação, mas a crise financeira e econômica internacional exigiu uma atuação mais proeminente, principalmente a partir de suas interligações com outras instâncias que buscavam regular o SFMI, a dizer o Comitê de Basileia para Supervisão Bancária (Basel Committee on Banking Supervision, BCBS, na sigla original em inglês) e o Conselho de Estabilidade Financeira (Financial Stability Board, FSB, ${ }^{1}$ na sigla original em inglês).

O regime regulatório internacional, marcado pelos Acordos de Basileia I e II no âmbito do $\mathrm{BCBS}^{2}$, sofreu alterações após a crise principalmente com a atuação do G-20 e com a interação do Comitê com o FSB, dando origem ao Acordo de Basileia III a partir de 2010. Entretanto, mesmo com mudanças, é possível afirmar que o novo regime regulatório "[...] não se despiu da lógica que parece ter contribuído para a gestação da crise; ao contrário, a manteve [...]” (MENDONÇA, 2012, p. 474). Embora cada acordo tenha buscado suprir limitações anteriores, a confiança na eficiência dos mercados e na autorregulação supervisionada continuou pautando seus conteúdos.

Posto isso, o principal objetivo deste artigo é demonstrar os desafios que existem na regulação do SFMI atualmente devido, dentre outros fatores, aos interesses estratégicos nacionais que, muitas vezes, são conflitantes. $\mathrm{O}$ artigo pretende analisar como o G-20 parecia uma plataforma promissora para discussão de medidas

$1 \quad$ O FSB foi criado em abril de 2009 como sucessor do Fórum de Estabilidade Financeira (Financial Stability Forum - FSF) com a ampliação do seu mandato. O FSB busca promover a estabilidade financeira internacional e fortalecer os sistemas financeiros com a coordenação entre as autoridades internacionais no desenvolvimento de uma estrutura regulatória e supervisória internacional (FINANCIAL STABILITY BOARD, 2016).

2 "O BCBS está constituído no âmbito do Bank for International Settlements (BIS). Até fevereiro de 2009, sua composição incluía os seguintes países: Alemanha, Bélgica, Canadá, França, Holanda, Itália, Japão, Suécia, Suíça, Reino Unido, Estados Unidos, Luxemburgo e Espanha. Em março de 2009, o órgão incorporou como membros Austrália, Brasil, China, Índia, México e Rússia" (FREITAS, 2012, p. 483). 
de regulação internacional em um primeiro momento, mas, justamente em função das assimetrias entre seus membros no contexto da crise, a implementação de suas propostas enfrentou desafios. Tal assimetria de interesses contribuiu para o aprofundamento da crise, o que revela, em última instância, que ela não foi um episódio isolado, mas sim o desdobramento de um movimento intrínseco das contradições que baseiam o próprio sistema de acumulação de capital em um contexto liberalizante e desregulamentado.

O artigo é composto por três seções, além da introdução e de considerações finais. A primeira seção se propõe a analisar o caráter instável da economia monetária de produção capitalista a partir da perspectiva de Minsky. A segunda seção objetiva discutir os agentes e instrumentos financeiros que marcaram a crise de 2007 e 2008, bem como a sua gestão pelos Estados Unidos e destaca a regulação internacional e como esta não foi suficiente para evitar uma nova crise, com impactos no sistema financeiro e monetário internacional. A terceira seção ressalta o histórico de criação do G-20 enquanto grupo de coordenação político e como foi sua atuação na gestão da crise recente, com destaque para sua contribuição na constituição da nova regulação financeira internacional, Basileia III. Ainda nessa seção, o artigo explora a eficácia das medidas que foram adotadas, mas também busca ir além, com uma análise que observa as discussões realizadas pelo G-20, suas propostas e, consequentemente, os desafios em sua implementação face às medidas adotadas de forma unilateral.

\section{A Natureza Inerentemente Instável do Capitalismo Contemporâneo}

A hipótese da instabilidade financeira (doravante HIF) de Minsky (1982) é uma tentativa de compreender o funcionamento de uma economia capitalista inerentemente instável e sujeita a crises que são geradas endogenamente. Segundo o autor, a economia funciona como "paradigma de Wall Street", no qual as práticas financeiras podem afetar decisões de investimento. Primeiramente, a HIF explica o comportamento cíclico da economia, que é resultado da interação entre investimento produtivo e finanças. Em períodos de estabilidade econômica, os agentes tenderiam a diminuir as suas margens de segurança, isto é, a diferença entre aquilo que esperam receber em receitas e seus custos, incluindo os serviços dos compromissos de endividamento. A instabilidade nasceria, assim, do processo de financiamento de ativos e dependeria de como os agentes montam a sua estrutura de passivo no tempo e avaliam os riscos dos projetos financiados.

O otimismo na fase ascendente do ciclo faz a proporção de empréstimos no balanço dos bancos aumentar e os fazem criar mais inovações financeiras. Ao mesmo tempo, os bancos diminuem as suas margens de segurança e emprestam para agentes que já estão endividados, já que os lucros auferidos pelos clientes os 
fazem rever sua estratégia e diminuir a percepção de risco, aumentando o "nível subjetivamente aceitável” (MOLLO, 1988, p. 106) de endividamento. A fragilidade financeira é, portanto, consequência dessa queda da percepção do risco e da mudança da preferência pela liquidez dos agentes econômicos (bancos, capitalistas e famílias), com redução nas margens de segurança (KREGEL, 2007). Os agentes vão, ao longo do ciclo, tomando posturas mais arriscadas, que são mais dependentes da valorização do ativo do que do fluxo de caixa futuro gerado pelo investimento realizado. A fragilidade transforma-se em instabilidade - crise - quando alteram-se as condições de financiamento e os agentes passam a ter dificuldades de arcar com os compromissos financeiros assumidos no passado: "When borrowers cannot meet repayment demands, cash-flow disruptions spread to other units' balance sheets, and portions of the economy's asset-liability structure is jeopardized [...]" (DIMSKY, 2013, p. 231). Nesse momento, os agentes precisam liquidar suas posições (sell position to make position) para conseguir recursos, já que é mais difícil conseguir refinanciamento no mercado, levando à queda no preço dos ativos. A economia entra, então, em um processo de debt deflation.

Com o valor do colateral dado nos empréstimos concedidos pelos bancos caindo em uma debt deflation, as instituições mais alavancadas podem tornar-se rapidamente insolventes. Como os bancos estão ligados pela rede de pagamentos com outras instituições financeiras, a falência de um banco pode comprometer o sistema todo, gerando risco sistêmico, ainda mais considerando-se um contexto em que, ciclicamente, o sistema todo se tornou mais frágil financeiramente. Quando a fragilidade torna-se instabilidade, somente o Big Bank (banco central), atuando como emprestador de última instância, e o Big Government, realizando política fiscal anticíclica, são capazes de barrar a espiral deflacionista dos preços dos ativos.

A instabilidade no sistema financeiro contemporâneo é derivada, em uma escala muito maior, da atuação alavancada dos grandes bancos em mercados financeiros complexos e pouco regulados, que faz surgir uma conexão não trivial entre os diversos mercados - o bancário tradicional, o monetário, o de capitais e de derivativos - e nas operações que realizam dentro e fora de balanço. A liquidez do sistema é volátil e depende de expectativas dos agentes fornecedores dessa liquidez, expectativas que não são subjetivas, mas sim conjuntas, um consenso de mercado - que Belluzzo (2012, p. 146) chama de "mimetismo competitivo". Este funciona tanto em momentos de otimismo, quando a alavancagem é generalizada, quanto em momento de crise, quando qualquer desconfiança por parte de um grande agente se reverte para um pânico geral e a liquidez necessária para manter o mercado funcionando é retirada.

Entretanto, mais do que a atuação do Big Bank e do Big Government, Minsky destaca a necessidade da regulação financeira. Para Minsky, o banco central, além de regulador, precisa ser o estabilizador do sistema financeiro e monetário, função 
que envolve garantir o bom funcionamento dos mercados, sendo emprestador de última instância não só em crises, mas em qualquer momento. No entanto, para isso, é necessária uma regulação das práticas financeiras que seja eficiente no sentido de evitar a deterioração das estruturas financeiras e, consequente, instabilidade. A economia é marcada por incerteza, com flutuações cíclicas; a regulação precisa estar presente para evitar excessos financeiros e especulação, e não para somente corrigir falhas de mercado - o que é um grande desafio no panorama contemporâneo.

\section{A Crise Financeira de 2007 e 2008}

Esta seção tem como objetivo principal analisar as origens da crise financeira e econômica de 2007 e 2008 através de um olhar que ressalte como foi um desdobramento do processo de liberalização financeira nos Estados Unidos e da atuação dos agentes financeiros em sua busca por lucro constante - o que foi potencializado com os novos instrumentos financeiros - e como isso afetou o SMFI, dada a intrínseca relação entre as economias nacionais.

Para tanto, a seção está dividida em duas partes. Primeiramente, será analisado, mesmo que de forma breve, alguns determinantes para o estouro da bolha imobiliária e como a gestão da crise foi feita pelas autoridades monetárias norte-americanas. Posteriormente, a análise se volta para o panorama das regulações internacionais, ressaltando os Acordos de Basileia I e II e suas fragilidades. Pretende-se demonstrar, assim, que existiam mecanismos de regulação prévios, mas que estes não foram necessariamente estruturados para evitar o excesso de especulação.

\subsection{A Crise do Subprime nos Estados Unidos: Agentes, Instrumentos e Gestão}

Com os efeitos devastadores da crise de 1929, os Estados Unidos iniciaram uma reforma financeira que tinha como objetivo evitar futuras crises e promover mecanismos para maior regulação por parte das autoridades monetárias norte-americanas; para tanto, a segmentação bancária, com a separação das atividades dos bancos comerciais e de investimento (através do Glass Steagal Act em 1933) foi a principal medida adotada, buscando garantir maior transparência nas atividades dos bancos (RODRIGUES, 2012, p. 19-20).

A estabilização foi alcançada e as autoridades monetárias passaram a possuir maior controle sobre o sistema. Porém, as inovações financeiras criadas a partir da década de $1970,{ }^{3}$ com destaque para os derivativos e o crescente aumento

3 “Muitas das chamadas 'inovações financeiras' nasceram como tentativas de burlar os controles. Porém, isso só significava que as regras tinham de ser frequentemente atualizadas - e não que a 
das pressões pela liberalização financeira, iniciaram um processo de desmonte do arcabouço de regulação formulado na década de 1930, culminando, em 1999, no Gramm-Leach-Bliley Act, que eliminou a segmentação bancária do Glass Steagal Act.

Moldava-se a nova arquitetura financeira internacional, mais baseada em um sistema financeiro com grandes conglomerados do que em instituições locais e regionais (embora estas continuem existindo, ainda que sofrendo constantes pressões competitivas dos grandes bancos). Essa nova arquitetura é fruto de um intenso processo de fusões e aquisições que, nos Estados Unidos, é representado pela redução no número de instituições bancárias, passando de 17,8 mil, em 1980, para 6,7 mil em 2014 (DEOS, 2015, p. 29). A concentração bancária foi acompanhada por um processo de crescente financeirização, que teria "[...] como característica central o crescente poder exercido pelos atores financeiros nas decisões de investimento, na precificação de variáveis macroeconômicas, na reestruturação produtiva das empresas [...]" (MELLO, 2013, p. 93).

Tem-se, assim, a presença relevante das finanças no seio das decisões que envolvem também o processo produtivo, bem como o aumento de ativos financeiros transacionados, fruto do processo de liberalização e desregulamentação. As inovações financeiras - dentre as quais há destaque inegável para os derivativos credit default swaps e produtos estruturados como os collateralized debt obligations - são essenciais para se compreender as origens da crise financeira e, posteriormente, econômica de 2007 e 2008.

Segundo Farhi (2011, p. 10), os agentes que aturam na deflagração e durante a crise e os instrumentos utilizados por esses agentes são essenciais para uma compreensão apurada da mesma. Em tal perspectiva de análise e longe de detalhar um processo extremamente profundo e marcado por diversos outros instrumentos financeiros, ressalta-se o processo de emissão e securitização ${ }^{4}$ das hipotecas subprime (hipotecas de alto risco concedidas para pessoas com histórico de crédito ruim ou limitado, as quais não foram honradas) nos Estados Unidos, processo que foi liderado por agentes financeiros específicos - compreendidos basicamente como os bancos comerciais, os bancos universais (que administram fundos e bancos de investimento) e instituições financeiras diversas, que passaram a fornecer maiores volumes de crédito baseados nas inovações financeiras e na chancela desses novos produtos pelas agências de classificação de risco. Nota-se

regulação fosse inviável [...]" (CARVALHO; KREGEL, 2010, p. 26).

4

"A lógica por trás da securitização é a transformação de obrigações de crédito em instrumentos negociáveis, o que gera maior liquidez aos ativos bancários. Assim, este processo foi uma resposta dos bancos comerciais ao aumento da concorrência com instituições não bancárias e à perda de rentabilidade das operações de crédito nos anos 1980. Com a securitização, a lógica de ganho passou a ser o diferencial de preços, o que gera elevado potencial desestabilizador, uma vez que estes preços são sensíveis a ondas de otimismo e pessimismo dos agentes" (RODRIGUES, 2012, p. 34). 
o otimismo na fase ascendente do ciclo, segundo a perspectiva de Minsky, que proporcionou aumento nos níveis de empréstimos dos bancos para agentes que já estão endividados.

Esses créditos eram fornecidos na forma de títulos, que eram negociados nos mais diversos mercados a partir de riscos e retornos diferenciados entre si. $\mathrm{O}$ processo de securitização, assim, se fortalecia. Além disso, “[...] esse modelo de negócios foi implementado pelo segmento de banco de investimento no seio dos bancos universais [...]" (FARHI, 2011, p. 14), o que agravou em grande parte os prejuízos dada a magnitude desse segmento, principalmente nos Estados Unidos.

Inicialmente, a crise foi vista como setorial e com pouca capacidade de transmitir danos aos demais setores da economia norte-americana, o que foi reforçado pelas autoridades monetárias do país. Entretanto, ao longo de 2007, a real profundidade da crise começou a ser revelada, o que inevitavelmente afetou o sistema financeiro dos Estados Unidos como um todo. A fragilidade e a instabilidade financeiras emergiram nesse panorama, e medidas precisavam ser tomadas pelas autoridades norte-americanas.

O Federal Reserve (FED) - banco central norte-americano - utilizou instrumentos de política monetária não tradicionais ${ }^{5}$ desde o início da crise - com destaque para a crescente diminuição das taxas de juros de curto prazo: em setembro de 2007, a taxa baixou para 4,75\% a.a. e, em 29 de outubro de 2008 , chegou a $1 \%$ a.a. (BULLIO et al., 2011, p. 345). No entanto, é interessante destacar que, a partir de dezembro de 2007, a política monetária não tradicional (ou discricionária) passou a ocupar maior espaço na atuação do FED, especialmente através dos programas de assistência financeira para estabilização e através da compra de ativos (BULLIO et al., 2011, p. 344).

Porém, mesmo com as políticas que buscavam a estabilização do sistema, a crise demonstrou seu caráter sistêmico e a profundidade das interconexões das instituições com a declaração de falência do Lehman Brothers em setembro de 2008, dado que o FED optou por não prestar socorro à instituição. ${ }^{6}$ Entretanto, a decisão de não interferir no caso desencadeou um movimento de desvalorização de ativos de forma generalizada, além do agravamento da paralisia de crédito e falta de liquidez, que começavam a afetar o sistema financeiro global (BLIKSTAD, 2011, p. 41), como ressaltado pela perspectiva de Minsky. Logo em seguida à quebra do Lehman Brothers, as autoridades monetárias norte-americanas alte-

5 Os instrumentos tradicionais de política monetária são o open market, o redesconto e o compulsório. Nesse sentido, os instrumentos não tradicionais (ou discricionários) de política monetária diferem das formas convencionais, sendo os programas de relaxamento monetário (quantitative easing) para compra de ativos um exemplo contemporâneo.

6 " [...] as autoridades americanas acreditavam que a falência deste banco de investimentos ajudaria a conter a crise, mostrando a firmeza da decisão política de deixar quebrar instituições financeiras [...] que estivessem envolvidas na generalização de práticas de negócio duvidosas [...]" (CARVALHO, 2012, p. 20). 
raram sua postura e passaram a intervir de forma ainda mais direta na economia através do FED e do Tesouro, com instrumentos monetários não tradicionais que buscavam conter a crise (BULLIO et al., 2011, p. 342). Para evitar que todo o seu sistema financeiro e bancário entrasse em colapso, houve a promoção de um resgate generalizado através de duas iniciativas, dentre inúmeras outras também importantes: o Troubled Asset Relief Program (Tarp), gerido pelo Tesouro e aprovado pelo Congresso em outubro de 2008, que destinava US $\$ 700$ bilhões para serem injetados na economia; e o Financial Stability Plan (FSP), divulgado em março de 2009 e que passou a fazer avaliações dos balanços patrimoniais bancários (BLIKS$\mathrm{TAD}, 2011$, p. 42).

O balanço do FED aumentou com a compra de ativos dos títulos considerados como podres das carteiras dos bancos, de forma a aliviar os impactos da crise imobiliária: "[...] entre setembro e dezembro de 2008, o balanço do FED passou de US $\$ 900$ bilhões para US $\$ 2,293$ trilhões, mantendo esse nível até setembro de 2009 [...]" (BLIKSTAD, 2011, p. 52). Percebe-se que as medidas do FED buscavam ampliar a liquidez da economia norte-americana através de política monetária. Entretanto, a transmissão dos efeitos da crise para a economia global era inevitável dada a íntima relação entre seus agentes e instituições. Assim, além das medidas internas tomadas pelos Estados Unidos, a necessidade de medidas em âmbito multilateral em relação à gestão da crise era evidente.

Paralelamente às ações extraordinárias de política monetária pelos bancos centrais, o formato da regulação bancária e financeira começou a ser revisto. No momento de agravamento da crise internacional, em setembro de 2008 o cronograma de implementação do Acordo de Basileia II ainda não havia sido concluído, o que fez com que houvesse ainda maior urgência na coordenação de políticas para enfrentar a crise. Nesse contexto, o G-20 ganhou papel de destaque com a discussão de medidas a serem tomadas principalmente no que tange à regulação do sistema financeiro internacional e com a adoção de Basileia III. A próxima subseção destina-se à análise da regulação financeira no ambiente de liberação.

\subsection{A Regulação Financeira Internacional: Análise Histórica Recente}

Conforme ressaltado anteriormente, as inovações financeiras e o processo de liberalização e desregulamentação das atividades financeiras e bancárias, especialmente a partir da década de 1980, são elementos essenciais para se compreender o panorama econômico contemporâneo. É possível afirmar que "[...] a combinação destes dois processos, inovações e desregulamentações, resultou em um forte movimento de mudança na estrutura financeira e de liberalização financeira [...]" (RODRIGUES, 2012, p. 34). 
Nesse contexto de transformações das práticas financeiras, os bancos comerciais passaram a atuar de forma cada vez mais proeminente no mercado de capitais - tornando-se fortes competidores dos próprios bancos de investimento, que começavam a utilizar a securitização de forma quase rotineira em suas operações (RODRIGUES, 2012, p. 35). Acentuava-se o processo de concentração bancária, o que culminou em grandes conglomerados que, beneficiados pelas inovações financeiras, atuavam cada vez mais no mercado financeiro, aumentando a fragilidade.

Ao mesmo tempo que o processo de liberalização se dava, discussões acerca da necessidade de regulações sobre a atividade financeira e bancária internacional eram levantadas pelos próprios Estados, buscando garantir o mínimo de organização e de eficiência. Foi criado, em 1974, o Basel Committee on Banking Supervision (BCBS), ou Comitê de Basileia, no âmbito do Grupo dos 10 (ou G-10), ${ }^{7}$ que tinha como objetivo discutir medidas a serem adotadas a fim de padronizar as práticas e regulações da arquitetura financeira internacional, sendo um grupo de natureza informal, responsável por dar recomendações aos seus membros no que tange à regulação bancária e financeira internacional. Seus trabalhos deram origem, em 1988, ao Acordo de Basileia I, adotado por mais de 100 países e com implementação prevista a partir de 1992 (FREITAS, 2012, p. 484).

Os objetivos principais de Basileia I eram garantir a estabilidade do sistema bancário internacional, bem como proporcionar um ambiente competitivo em termos financeiros. Para tanto, "[...] a ideia central do Acordo era de que os bancos deveriam manter níveis mínimos de capital para cada um dos instrumentos negociados em seus ativos, em função da percepção de risco de cada um desses instrumentos [...]" (RODRIGUES, 2012, p. 35). Isso seria medido através de um índice definido em no mínimo 8\%. Basileia I é caracterizado pela regulação microprudencial, que foca especificamente nos bancos de forma individual. Entretanto, o acordo foi criticado desde suas origens. Dentre as críticas, há destaque para o foco exclusivo na avaliação do chamado risco de crédito, não levando em consideração outros tipos de risco, como os riscos de mercado e de taxa de juros. Ao mesmo tempo, Basileia I estava baseado em modelos de requerimento de capital com ponderações fixas de risco (RODRIGUES, 2012, p. 35).

Diante desse quadro, o BCBS formulou uma emenda, que foi adicionada ao acordo em 1996. Em linhas gerais, essa emenda buscou proteger as instituições financeiras em relação aos riscos de preços através da incorporação do risco de mercado e de taxa de juros: "[...] na prática, foram estabelecidas metas de capital para cobrir posições abertas dos bancos quanto a moedas estrangerias, opera-

7 Formado em 1962, o Grupo dos 10 (G-10) é composto por Alemanha, Bélgica, Canadá, Estados Unidos, França, Itália, Japão, Países Baixos, Reino Unido, Suécia e Suíça. Tais países aderiram ao Acordo Geral para Obtenção de Empréstimos no âmbito do Fundo Monetário Internacional. 
ções com securities, ações, commodities e opções [...]" (RODRIGUES, 2012, p. 36). Embora a harmonização da legislação tenha sido perseguida, distorções causadas pelos seus mecanismos de regulação (principalmente pelo regime de ponderações fixas de riscos) não foram evitados, e os bancos passaram a recorrer crescentemente à arbitragem e à securitização.

Assim, não foi surpresa quando as discussões para a criação de um novo acordo se iniciaram em 1999, após uma década marcada por diversas crises financeiras (com destaque para a brasileira, a russa e a asiática). Iniciava-se o processo de negociação do Acordo de Basileia II, que foi oficialmente finalizado em 2004 e atualizado em 2006. Seu principal objetivo era a superação das limitações da regulação anterior através de maior flexibilidade nas regras e um arcabouço regulacionista mais diversificado.

O núcleo de Basileia II consiste no incentivo à utilização de instrumentos que melhorem a gestão de risco das instituições financeiras (FREITAS, 2012, p. 485). Além disso, é composto por três pilares complementares entre si, que são: a) a exigência de um capital mínimo, que varia de acordo com a exposição das instituições aos riscos de crédito, de mercado e operacional (pilar 1); b) o papel de destaque dado aos órgãos supervisores no que tange à observação das ações das instituições financeiras internacionais, que devem considerar não somente os riscos normalmente tomados internamente, mas também fatores externos (pilar 2); c) o incentivo à divulgação pública de informações oficiais sobre a saúde financeira da instituição, o que deve ser feito com uma determinada periodicidade (pilar 3) (FREITAS, 2012, p. 485-486). ${ }^{8}$

Evidencia-se que Basileia II garante grande poder de gestão de risco para as instituições financeiras, que se tornam as próprias responsáveis por disciplinarem seus riscos. Há uma grande crença no poder de autorregulação do mercado e, sobretudo, uma crença de que a solvência do setor bancário internacional como um todo é a soma da solvência individual de cada banco. Logo, desde que os bancos possuam condições adequadas individualmente, presume-se que os riscos sistêmicos são quase nulos.

Com um olhar mais atento, é possivel notar que essa mentalidade condiz com o panorama dos anos 2000 de forma geral. O sistema e suas instituições bancárias, retroalimentando-se com suas próprias avaliações de risco positivas, incentivavam a pró-ciclicidade do crédito bancário (FREITAS, 2012, p. 487), movimento visto

8 "O Acordo de Basileia não é sobre reservas em dinheiro nem sobre se os bancos podem ou não usar todo o dinheiro que têm. O Acordo de Basileia baseia-se em coeficientes de capital, que estão relacionados a fontes de recursos: um banco (ou qualquer outra empresa) pode comprometer os próprios recursos (isto é, seu patrimônio líquido ou capital acionário fornecido pelos donos) ou recursos emprestados por terceiros. Em princípio, um intermediário financeiro não precisa ter nenhum capital. Pode pedir emprestado de quem tem recursos e emprestar esse montante. O que Basileia II diz é que eles têm de manter, por ordem dos reguladores, alguns recursos próprios" (CARVALHO; KREGEL, 2010, p. 31). 
especialmente nos Estados Unidos. Observa-se um comportamento pró-cíclico por parte dos bancos - reforçado institucionalmente por Basileia II - que pode ser resumido da seguinte maneira:

Basileia II apresenta uma característica essencialmente microeconômica. Considerando um período econômico estável, este instrumento impede que bancos individualmente assumam riscos maiores ou possuam exposições mais arriscadas que o padrão considerado aceitável naquele momento. Contudo, ao não capturar a evolução das expectativas da economia de modo agregado, deixa de ser efetivo nos momentos de instabilidade. Pior, ao embutir em seus mecanismos fatores decorrentes das expectativas da economia, estimula os fatores que concorrem para sua ocorrência (FREITAS, 2012, p. 488).

Ressalta-se que os Acordos de Basileia buscam a harmonização de regras no que concerne à supervisão e à regulação das atividades das instituições financeiras internacionais, buscando garantir que os bancos tenham capital suficiente, de forma individual, para enfrentar as crises que possam surgir, "[...] mas as regras criadas por eles mostram-se muito frágeis e suscetíveis de serem contornadas, sobretudo porque estão baseadas na premissa da eficiência dos mercados e da gestão de riscos dos bancos [...]" (FARHI, 2011, p. 24). As premissas das regulações, baseadas essencialmente na hipótese dos mercados eficientes, não foram questionadas ao longo da evolução dos acordos, perpetuando-se uma estratégia que seria desmoralizada pela própria crise (CARVALHO; KREGEL, 2010, p. 37). Além disso, a decisão de adotar e implementar a estrutura regulatória dos mesmos é uma decisão nacional e pode ser realizada em ritmos diferentes - o que é mais um desafio.

Tal panorama é essencial para a compreensão acerca do papel do G-20 na crise de 2008 e de suas propostas de regulação feitas em conjunto com o FSB e o próprio Comitê de Basileia, que passaram a atuar de forma próxima após a crise (MENDONÇA, 2012, p. 454).

\section{Propagação da Crise e Propostas de Regulação: o G-20}

Tendo-se analisado o histórico da crise financeira e econômica de 2007 e 2008, bem como as regulações financeiras internacionais (a dizer Basileia I e II), torna-se um imperativo analisar o papel que o Grupo dos 20 (G-20) desempenhou na busca por uma gestão conjunta da crise. O argumento desta seção está dividido em dois momentos. Primeiramente, será analisado o contexto de criação do G-20 e suas principais características; será ressaltado, através de uma visão crítica, como o grupo foi uma plataforma de concertação política durante os anos 2000.

Em um segundo momento, será analisado como o G-20 ganhou destaque no contexto de crise financeira e econômica, tendo sido convocado em um momento crítico e reunido as principais lideranças em busca de propostas de regulação in- 
ternacional. A criação do Conselho de Estabilidade Financeira, que se reportava diretamente ao G-20, e sua ligação com o Comitê de Basileia serão analisados de forma a ressaltar as principais medidas acordadas - e os desafios que se perpetuam com a adoção de políticas nacionais unilaterais mesmo com as tentativas de concertação multilateral.

\subsection{O G-20 e o Sistema Financeiro Internacional: Origem e Atuação antes da Crise}

Neste momento, torna-se importante ressaltar o contexto de criação do Grupo dos 20 na década de 1990 até a emissão do seu primeiro comunicado, em dezembro de 1999. Tal década foi marcada por diversas crises especulativas (como a brasileira) e ataques financeiros, além de diversos planos de recuperação das economias afetadas. O Fundo Monetário Internacional (FMI) passou a desempenhar um papel proeminente no processo de recuperação, com pacotes de ajuda concedidos diante de reformas institucionais aplicadas pelos países que recorriam a ele. Entretanto, tais reformas implicavam em contração de gastos públicos e elevação das taxas de juros em prol da estabilização financeira, dentre outras condicionalidades, o que contribuiu para agravar as crises instaladas em diversos países que recorreram ao FMI (CARVALHO, 2012, p. 19-20).

O FMI passou a ser considerado uma instância representativa dos interesses dos países desenvolvidos. Tal panorama "[...] levou muitos países a pelo menos considerarem a hipótese de abandonar o sistema, criando instituições alternativas, especialmente de caráter regional [...]" (CARVALHO, 2012, p. 20). Logo, o G-20 foi idealizado como uma alternativa a instituições como o FMI, ao mesmo tempo que buscava manter a ordem econômica vigente desde o colapso de Bretton Woods. O grupo passou a buscar uma articulação política que promovesse o crescimento econômico de forma estável e sustentável, ressaltando a importância de coordenação para construir um sistema menos propenso a crises.

Embora tenha sido criado como uma instância alternativa ao FMI, de certa maneira o G-20 não deixou de estar muito próximo a ele desde as suas origens, o que marca seu duplo caráter como grupo de coordenação política. O G-20 foi composto por países desenvolvidos mais as economias dos chamados "países emergentes", que, segundo Carvalho (2012, p. 21), possuíam grande interesse em constituir uma instância complementar ao FMI. São seus membros: Argentina, Austrália, Brasil, Canadá, China, França, Alemanha, Índia, Indonésia, Itália, Japão, México, Coreia do Sul, Rússia, Arábia Saudita, África do Sul, Turquia, Reino Unido, Estados Unidos e União Europeia. Os países emergentes buscavam ressaltar suas necessidades e questionamentos relacionados à arquitetura financeira internacional; os países desenvolvidos buscavam transmitir suas experiências no que dizia 
respeito à governança e, em grande medida, preservar seus interesses (CARVALHO, 2012, p. 21).

Observa-se que G-20 foi criado como um fórum no qual discussões pudessem ser feitas entre seus membros informalmente; ele não é uma organização internacional propriamente dita, mas sim um fórum sem regras formais de constituição e de operação. Sua agenda é formada pelos interesses postos pelos líderes nacionais reunidos e sua autoridade está relacionada somente ao “[...] compromisso moral que seus membros decidam assumir [...]" (CARVALHO, 2012, p. 24). Todos os países possuem poder igual de voto nas discussões, não há hierarquia explícita e busca-se o consenso nas questões discutidas. Além disso, o G-20 não possui uma sede: suas reuniões acontecem nos países que presidem os encontros (ALVES, 2015, p. 137).

Ao longo dos anos 2000, o G-20 emitiu diversos comunicados oficiais que não possuíam teor crítico em relação às estratégias econômicas adotadas por seus membros, as quais eram marcadas pela liberalização de capitais - o que havia contribuído para as crises da década de 1990. Pode-se observar, portanto, que

[...] a crise asiática, a russa, a brasileira etc. não haviam ensinado que a liberalização da movimentação de capitais era perigosa, mas sim que ela deveria ser precedida de outras reformas liberalizantes. O que era necessário não era reavaliar a conveniência da liberalização, mas o sequenciamento de reformas que levaria a ela, que permanecia com objetivo indiscutível das políticas de governo (CARVALHO, 2012, p. 22).

De uma forma geral até 2007, o grupo exaltava, em seus comunicados, as taxas de crescimento das economias mesmo com as consideradas pequenas turbulências financeiras que já aconteciam. Naquele ano, o G-20 havia centralizado seus esforços em observar como era possível alcançar melhores níveis de gastos e de alocações de recursos, visando sempre ao aumento da eficiência econômica. Porém, o agravamento da crise financeira norte-americana com a falência do Lehman Brothers mudou o rumo de atuação do G-20 de forma definitiva, alterando, inclusive, seu raio de ação (CARVALHO, 2012, p. 24) na busca por contenção dos efeitos da crise, principalmente no que tange o SFMI.

\subsection{G-20 na Crise e suas Propostas}

A crise desnudou o fato de que as regulações internacionais, a dizer Basileia I e II, não eram suficientes para garantir a estabilidade financeira internacional. Com o agravamento da crise a partir de setembro de 2008, o G-20 tornou-se o fórum de discussões e de tomada de decisões de políticas que, se não eram estruturalmente internacionais, pelo menos seriam coordenadas internacionalmente (MENDONÇA, 2012, p. 453). 
Contudo, tal tarefa mostrou ser de difícil gerência mesmo por um grupo relativamente pequeno, mas que ampliou sua agenda de forma drástica após a crise, sem perder o seu caráter conservador de atuação, o que remonta às suas origens (CARVALHO, 2012). A gestão da crise com medidas unilaterais adotadas pelos Estados Unidos e por outros países também afetaram as decisões de todas as instâncias multilaterais que debatiam sobre como enfrentar a crise no curto e longo prazos. Porém, mesmo assim, nos anos iniciais posteriores à crise, o G-20 não deixou de ser o fórum que debateu medidas a serem tomadas: "[...] o G-20 afirmou a existência de um consenso entre os países-membros sobre a urgente necessidade de reformar profundamente a supervisão e a regulação financeira, no intuito de prevenir a ocorrência de eventos semelhantes [...]" (FARHI, 2011, p. 23).

Nesse sentido, a primeira reunião do G-20 após a crise foi convocada entre os chefes de Estado e de governo em novembro de 2008, em Washington, Estados Unidos, com o intuito de debater a profundidade da crise e como lidar com seus impactos. Nenhuma ação específica foi tomada pelo G-20, mas houve o reconhecimento de que os sistemas de regulação dos principais países desenvolvidos não eram isentos de falhas (FREITAS, 2012, p. 489-490), o que precisaria ser melhorado com a busca de transparência, reforma de instituições nacionais e internacionais e aumento da regulação. A reunião buscou fortalecer a ideia de que o G-20 tinha capacidade para tomar decisões que deveriam ser implementadas (COOPER; BRADFORD, 2010, p. 6).

Continuando com suas reuniões e discussões, o G-20 reuniu-se novamente em abril de 2009, em Londres, para encaminhar medidas práticas que tangenciassem o arcabouço regulatório internacional - a dizer, o escopo e objetivo da nova regulação (MENDONÇA, 2012, p. 454). O grupo estabeleceu o Conselho de Estabilidade Financeira (Financial Stability Board - FSB), que se tornou a instância responsável por regular o mercado de derivativos e supervisionar as atividades financeiras das grandes instituições (ALVES, 2015, p. 237), além de: a) promover a coordenação entre as autoridades responsáveis pela estabilidade financeira; b) apoiar planos de contingência em caso de crises futuras; c) trabalhar com o FMI no que está relacionado à identificação de riscos sistêmicos, entre outros. O FSB deveria se reportar diretamente ao G-20 (MENDONÇA, 2012, p. 457).

O diagnóstico sobre a crise por parte do G-20 e do FSB, em última instância, não apontava o processo de liberalização ou os acordos de regulação financeiras firmados anteriormente. Pelo contrário, o G-20 determinou, através da articulação parcial das agendas do FSB e do Comitê de Basileia, que o Acordo de Basileia II deveria ser implementado de forma mais intensa e definitiva principalmente nos países mais avançados. Para além do reforço das medidas anteriores, o G-20 buscou aumentar, segundo Carvalho (2012, p. 26), as "[...] exigências de capital em relação aos ativos ponderados pelo risco, às quais deveriam se somar exigências 
em termos da manutenção de colchões adequados de liquidez nas instituições bancárias [...]”. Iniciava-se a formulação de um conjunto de medidas e regras que seriam finalmente aprovadas pelo G-20 no final de 2010: Basileia III.

As primeiras reuniões do FSB buscaram garantir o fortalecimento do regime de capital e de criação de liquidez em conjunto com o BCBS. O primeiro pacote de medidas redesenhadas pelo comitê tornou-se o rascunho do que viria a ser o Acordo de Basileia III, aprovado pelos membros do FSB. Assim, em setembro de 2010, a publicação oficial de Basileia III pelo comitê ocorreu com a aprovação do FSB, que passou a buscar especialmente a formação de um sistema bancário mais resiliente a crises. Em termos gerais, Basileia III buscou: a) redesenhar o regime de capital a partir de uma perspectiva que levava em consideração a sua qualidade no sistema bancário; b) garantir o alargamento da cobertura de risco; c) trabalhar com colchões de capitais para bancos individuais, ressaltando a importância da resiliência principalmente em momentos de estresse financeiro; e d) garantir resultados macroprudenciais de proteção ao sistema bancário no que tange ao crescimento de crédito, entre outras medidas específicas (MENDONÇA, 2012, p. 466-469).

Ao mesmo tempo, “[...] apesar de Basileia III poder ser entendida como o 'carro chefe' da reforma [...], a proposta do FSB parece tratar as mudanças de forma mais ampla [...]” (MENDONÇA, 2012, p. 461). O FSB, embora tenha concordado com as medidas de Basileia III, também desenvolveu uma agenda própria de discussão que remete: a) ao tratamento das chamadas instituições financeiras sistematicamente importantes, cuja interconexão pode acarretar graves danos ao sistema financeiro em casos de crises; b) à atuação de forma coordenada de autoridades nacionais no tratamento de questões relevantes; c) às regulações aplicadas e supervisadas nas instituições nacionais; d) à atuação no FSB de forma a garantir a efetividade e a constância das políticas nacionais, entre outros.

O G-20 tentou garantir, por meio do FSB nas reuniões de 2009 e de 2010, que medidas acordadas fossem implementadas de forma plena, visando alterar as práticas do sistema financeiro internacional. Entretanto, é possível constatar que a implementação de tais reformas era uma tarefa de difícil execução, dado que o prazo para a implementação das regras acordadas de Basileia III é 2019. Em primeiro lugar, após décadas de liberalização, a unificação de organismos que pudessem implementar regulações e executá-las de forma apropriada era uma tarefa de dimensões inimagináveis:

[...] a crise mostrou que a interpenetração de balanços se estende por meio das fronteiras. O ideal seria que estas normas fossem adotadas internacionalmente e que houvesse um organismo de supervisão e regulação. Mas esse ideal se confronta com fortíssima resistência dos governos, em particular o dos Estados Unidos. As propostas de reformas tendem a ser assim nacionais. Contudo, devido à sua diversidade, é necessário 
que elas sejam ao menos coerentes entre si; para que, posteriormente, seja possível buscar harmonizá-las internacionalmente (FARHI, 2011, p. 25-26).

Portanto, é possível concluir que um dos principais desafios para a harmonização de regras no sistema financeiro internacional são as persistentes assimetrias de interesses dos Estados, mesmo quando há uma crise sistêmica que afeta suas economias. É importante destacar também que a própria rigidez de regras criadas, mesmo quando reformuladas, é parte de uma problemática complexa, visto que o sistema é extremamente dinâmico e que as regras acordadas dificilmente atendem de forma uniforme aos interesses nacionais, dada a própria assimetria financeira internacional (FREITAS, 2012, p. 489). Além disso, inovações financeiras são postas em prática enquanto as regulações tendem a ser elaboradas posteriormente, não atuando para que mudanças nas estruturas financeiras de fato ocorram.

Os Estados Unidos, local de origem da crise, agiram de forma a promover liquidez através de suas políticas discricionárias e, mesmo que tivessem se comprometido a aprofundar a cooperação internacional no que diz respeito à regulação, não deixaram de demonstrar profunda discordância com a criação de um órgão regulador supranacional, o que foi considerado em determinados momentos (FARHI, 2011, p. 23). Além disso, durante a administração do presidente Barack Obama, legislações foram aprovadas pelo Congresso no que tange a regulação financeira, com destaque para o Dodd-Frank Wall Street Reform and Consumer Protection Act (DFA), ${ }^{9}$ aprovada pelo Congresso dos Estados Unidos em julho de 2010. Contudo, tal lei possui limitações e, apesar de trazer mudanças importantes no marco regulatório dos Estados Unidos, "[...] não tem a intenção de ser uma regulação ativa e que visa guiar as transformações das estruturas financeiras [...]" (RODRIGUES, 2012, p. 31).

A União Europeia (UE) adotou diferentes formas de gerir a crise através do Banco Central Europeu (BCE), que buscou promover a estabilidade do sistema bancário e a continuidade do fluxo creditício para as economias. O FED e o BCE atuaram em conjunto em dezembro de 2007, mas o fato de não ter havido coordenação entre suas políticas de forma mais contundente - mesmo ambos sendo parte do G-20 e de demais instituições que debatiam a questão da crise - demonstra novamente o fato de que as assimetrias de interesses nacionais pauta o debate sobre regulações internacionais contemporaneamente.

9 Um elemento central dessa peça foi a criação do Financial Stability Oversight Council, que tem como objetivo identificar todos os possíveis riscos à estabilidade financeira nos Estados Unidos. Ele deve definir e monitorar as atividades das chamadas instituições sistematicamente importantes - aquelas que, ao enfrentarem riscos individuais, também representam ameaça sistêmica (DEOS, 2015, p. 30-31). Além disso, a Lei Dodd-Frank estabeleceu regras que visavam a diminuir as operações de derivativos de balcão e criou, com a chamada regra de Volcker, restrições ao uso de fundos próprios por parte das instituições financeiras em atividades especulativas, entre outros tópicos. 
É importante destacar, contudo, que países como a Alemanha e a França, especialmente, empreenderam reformas nacionais relacionadas ao conteúdo de Basileia III, havendo destaque para tal fato em relatórios do FSB a partir de 2012. Dentre as reformas empreendidas pela Alemanha, por exemplo, pode-se destacar a reestruturação financeira de bancos do país e a recondução das atividades das instituições em condições fragilizadas de acordo com as novas regras (ALVES, 2015, p. 264). Além disso, a UE tem implementado a união bancária na zona do euro e "[...] em dezembro de 2013, consolidou o acordo que deu ao Banco Central Europeu poderes para supervisionar entre 100 e 200 instituições bancárias da região, fato que, na prática, tornou esse banco o órgão regulador central da zona do euro [...]" (ALVES, 2015, p. 264).

Ao mesmo tempo, o G-20 e o FSB, instância responsável por articular as mudanças regulatórias, perderam destaque no desenrolar da crise, sendo relegados a um segundo plano justamente porque seus membros, embora tivessem declarado inicialmente a coordenação de interesses, tenham optado, em termos gerais, por caminhos unilaterais. E, com o passar do tempo, as instituições bancárias começaram a apresentar melhoras em seus balanços, pois foram amplamente socorridas sem nenhuma contrapartida - e, como consequência da melhora de sua saúde financeira, seu poder de barganha contra possíveis regulações vindouras aumentou exponencialmente (FARHI, 2011, p. 26-27).

Assim, "[...] políticas monetárias continuam a ser adotadas de forma independente, desprezando completamente seus efeitos sobre outros países e não há qualquer sinal no horizonte de que exista disposição em mudar essa situação [...]" (CARVALHO, 2012, p. 27). Os desafios enfrentados pelo G-20 como um fórum multilateral de discussão revelam uma problemática sistêmica, pois os sistemas financeiros estatais continuam coexistindo em um contexto de crescente interligação. Os impasses não foram neutralizados pelas tentativas de harmonização de regras - as quais também apresentam diversos questionamentos em relação ao que pauta o seu conteúdo e o próprio monitoramento da regulação.

\section{Considerações Finais}

A arquitetura do sistema financeiro e monetário internacional passou por diversas transformações, especialmente a partir da segunda metade do século XX em diante. A liberalização e desregulação, a partir da década de 1980, são parte de um processo histórico que marca uma etapa muito específica do capitalismo contemporâneo, na qual as crises não deixam de existir - pelo contrário, se tornam mais explícitas - e na qual os Estados nacionais continuam a desempenhar papeis cruciais. 
A crise financeira e econômica de 2007 e 2008 ressaltou tais aspectos ao mesmo tempo que demonstrou a importância - e os desafios - da governança global no que está relacionado à arquitetura financeira internacional. O Grupo dos 20 foi uma instância que reuniu diversos líderes nacionais em um período crítico, sendo, assim, uma iniciativa de governança do SMFI. Entretanto, conforme demonstrado ao longo do presente artigo, a articulação de uma estratégia comum em um grupo tão heterogêneo como o G-20, em um contexto de crescente instabilidade financeira como ocorria na época da crise, mostrou-se uma tarefa delicada e com limitações.

É evidente que medidas foram adotadas tanto através do G-20 quanto em outras instâncias - com grande destaque para o Acordo de Basileia III. Ao mesmo tempo, as estratégias nacionais foram diversificadas, o que ressalta as diferenças entre os sistemas financeiros nacionais e o internacional: "[...] a ausência neste último de instituições reguladoras dotadas de poderes abrangentes de regulação e uniformização estrutural [...]" (CARVALHO et al., 2015, p. 242). Os Estados Unidos utilizaram instrumentos de política monetária não tradicionais, além de terem aprovado regulações como a Lei Dodd-Frank. A União Europeia, por sua vez, realizou reformas mais relacionadas às medidas propostas pelo FSB em um contexto de contenção de gastos públicos e de início da crise da zona do euro.

Contudo, reformas de instituições internacionais, como o FMI, não foram adiante, e o próprio G-20 perdeu destaque na condução de diálogos sobre a arquitetura financeira internacional contemporânea. É importante destacar que:

[...] apesar dos seus limites enquanto iniciativa de governança, é também muito possível lançar uma interpretação positiva sobre o G-20 e os resultados positivos nas áreas da governança monetária e financeira - sugestão que não contradiz com o tom limitado dos resultados atingidos em termos de governança [...]. Por meio dessa interpretação, o fórum reflete um parcial sucesso por ter contado com a presença de novas peças influentes no tabuleiro econômico e político global - as economias emergentes, atores influentes e com peso no SMFI (ALVES, 2015, p. 222-223).

Os marcos regulatórios internacionais e nacionais transformam-se com o passar do tempo, bem como os interesses daqueles que comandam as máquinas estatais e que influenciam diretamente tais legislações. Assim, o sistema internacional, mesmo pautado pelo modo de produção capitalista (com grande destaque para a sua lógica financeira) e pela presença dos Estados nacionais, também está em constante transformação. A crise de 2007 e 2008 trouxe questionamentos pertinentes, e medidas foram tomadas, porém, passados os anos, novas questões levantam mais desafios à chamada governança do SFMI - e crises não deixam de fazer parte dos cenários. 


\section{Referências}

ALVES, R. M. Crises, poderes, interesses e estratégias: o G-20 e a governança monetária e financeira contemporânea. 2015. Tese (Doutorado) - Programa de Pós-Graduação em Relações Internacionais San Tiago Dantas, Pontifícia Universidade Católica de São Paulo, São Paulo, 2015.

BELLUZZO, L. G. O Capital e suas metamorfoses. São Paulo: Ed. UNESP, 2012.

BLIKSTAD, N. M. D. Liberalização, desregulamentação e a crise global de 2007-2008. 2011. Trabalho (Conclusão de Curso) - Instituto de Economia, Universidade Estadual de Campinas, Campinas, 2011.

BULLIO, O.; FERRARA, D.; CUNHA, P.; CARVALHO, C. A atuação do FED antes e depois do estouro da bolha imobiliária: discricionariedade e mandato de bancos centrais em contexto de desregulamentação financeira. Economia e Sociedade, v. 20, n. 2 (42), p. 329-364, 2011.

CARVALHO, F. C. O G20 e a reforma do sistema financeiro: possibilidades e limitações. In: CINTRA, M. A. M.; GOMES, K. R. (org.). As transformações no sistema financeiro internacional. Brasília: IPEA, 2012. v. 1, p. 15-29.

CARVALHO, F. C.; KREGEL, J. A. O que fazem os sistemas financeiros e seus reguladores? Rio de Janeiro: IBASE, 2010. p. 1-42.

CARVALHO, F. C.; SOUZA, F.; SICSÚ, J.; PAULA, L. F.; STUDART, R. Economia monetária e financeira: teoria e política. Rio de Janeiro: Elsevier, 2015.

COOPER, A. F.; BRADFORD JR., C. I. The G-20 and the post-crisis economic order. CIGI G20 Papers, n. 3, 2010, p. 1-16.

DEOS, S. Transformações no sistema bancário norte-americano e o papel da regulação. Revista Política Social e Desenvolvimento, n. 23, ano 3, p. 26-33, 2015.

DYMSKI, G. "Can the US economy escape the law of gravity? A Minsky-Kalechi approach to the crisis of neoliberalism". In: YAGI, K. et al. (ed.). Crisis of global economies and the future of capitalism: reviving Marxian crisis theory. New York: Routledge Studies in the Modern World Economy, 2013.

FARHI, M. Crise financeira e reformas da supervisão e regulação. Texto para Discussão n. 1581. Brasília: IPEA, 2011. p. 1-39.

FINANCIAL STABILITY BOARD. About the FSB. In: FINANCIAL stability board. 2016. Disponível em: http://www.fsb.org/about/. Acesso em: 11 nov. 2017.

FREITAS, J. T. De Basileia II para Basileia III: os mesmos desafios? In: CINTRA, M. A. M.; GOMES, K. R. (org.). As transformações no sistema financeiro internacional. Brasília: IPEA, 2012. vol. 2, p. 479-499.

KREGEL, J. The natural instability of financial markets. The Levy Economics Institute of Bard College, 2007. 
MELLO, G. S. Os derivativos e a crise do subprime: o capitalismo em sua "quarta dimensão". 2013. Tese (Doutorado) - Instituto de Economia, Universidade Estadual de Campinas: Campinas, 2013.

MENDONÇA, A. R. R. Regulação bancária e arranjo institucional pós-crise: atuação do Conselho de Estabilidade Financeira e Basileia III. In: CINTRA, M. A. M.; GOMES, K. R. (org.). As transformações no sistema financeiro internacional. Brasília: IPEA, 2012. vol. 2, p. 441-477.

MINSKY, H. The financial instability hypothesis: an interpretation of Keynes and an alternative to "standard" theory". In: MINSKY, H. Can "it" happen again? Essays on Instability and Finance. New York: M. E. Sharpe, 1982. p. 59-70.

MOLLO, M. L. Instabilidade do capitalismo, incerteza e papel das autoridades monetárias: uma leitura de Minsky. Revista de Economia Política, v. 8, n. 1, p. 100-123, jan/mar. 1988.

RODRIGUES, D. B. Propostas de regulação pós-crise: um estudo do Dodd Frank Act e Basileia III. 2012. Trabalho de Conclusão de Curso (Bacharelado em Ciências Econômicas) - Instituto de Economia, Universidade Estadual de Campinas, Campinas, 2012.

Recebido em: 15/12/2017. Aceito em: 05/04/2018. 